\title{
Salt Tolerance in the Halophyte Suaeda maritima L. Dum.- - the Effect of Oxygen Supply and Culture Medium on Growth
}

\author{
Gazala M. Alhdad $^{1,2} \cdot$ Timothy J. Flowers $^{1}$ \\ Received: 3 April 2020 / Accepted: 4 November 2020 / Published online: 23 December 2020 \\ (C) The Author(s) 2020
}

\begin{abstract}
Suaeda maritima is an annual species that grows in salt marshes and tolerates not only salt but also flooding, although plants are smaller at lower than at higher elevations of salt marshes. We investigated whether adventitious roots play a role in tolerance to flooding and how flooding affects ion accumulation in the shoots, a determinant of growth in this species. We examined the response of plants grown in Stout and Arnon culture solution to different periods of flooding at different salinities and verified our results with plants grown in other culture solutions (Hoagland and Yoshida). We measured growth, photosynthesis and estimated stomatal frequency as well as the accumulation of $\mathrm{Na}^{+}, \mathrm{Ca}^{2+}, \mathrm{Mg}^{2+}$ and $\mathrm{K}^{+}$: plants grew and photosynthesised optimally in 200$\mathrm{mM} \mathrm{Na}^{+}$(in Stout and Arnon solution), but the optimal concentration for growth increased to $450 \mathrm{mM}$ when in Yoshida solution. Flooding always decreased growth, but had little effect on $\mathrm{Na}^{+}$concentrations. Although plants produced adventitious roots, their mass decreased rather than increased with flooding. The decrease in production of adventitious roots under flooded conditions suggested that they were not important in the tolerance of this species to submergence — an unusual response compared with the general response of flooding-tolerant plants.
\end{abstract}

Keywords Suaeda maritima $\cdot$ Halophyte $\cdot$ Salinity $\cdot$ Salt-tolerance $\cdot$ Flooding $\cdot$ Hypoxia

\section{Introduction}

Coastal salt marshes vary not only in salinity but also in elevation and consequently in the frequency of tidal inundation. At lower levels, plants may be covered with seawater twice daily, but at higher elevations, this may be monthly or even less frequently. With the increases in sea level consequent upon climate change, tolerance of flooding is likely to be an important factor in the zonation of plants on salt marshes (Tabot and Adams 2019) Suaeda maritima grows across salt marshes, but plants are smaller at lower than at higher elevations (Wetson and Flowers 2010; Alhdad et al. 2013). Such differences in growth can be replicated in plants cultured in a

Timothy J. Flowers

t.j.flowers@sussex.ac.uk

Gazala M. Alhdad

gazm2005@yahoo.com

1 School of Life Science, University of Sussex, Falmer, Brighton BN1 9QG, UK

2 Department of Plant, Faculty of Science, University of Sirte, Sirte, Libya greenhouse with different degrees of flooding, where growth is poorer in a flooded sand/mud mixture than in flooded sand alone; the sand/mud mixture had a lower redox potential (Eh) than the sand (Wetson and Flowers 2010). Flooding increases the concentration of antioxidants in the shoots (Alhdad et al. 2013) and of $\mathrm{Mn}$ and $\mathrm{Fe}$ in shoots and roots; Fe reaches potentially toxic concentrations (Alhdad et al. 2015).

The reasons for reduced growth where the substrate is frequently inundated with seawater are not clear. Roots regularly experience severe hypoxia following tidal inundation as do the submerged shoots during night time submergence (Colmer et al. 2013). Oxygen produced by underwater photosynthesis may prevent severe hypoxia during daytime submergence. However, during the hours of darkness, reduced ATP production in the roots is likely and S. maritima accumulates high concentrations of lactate (Colmer et al. 2013), presumably associated with ATP synthesis. Investment in lactate dehydrogenase (LDH) may be a contributory factor for reduced growth. Other possibilities are the cost of compartmentation of increased shoot $\mathrm{Na}^{+}$; the consequences of reduced shoot $\mathrm{K}^{+}$concentrations relative to plants growing at higher redox potentials (Wetson and Flowers 2010), investment in antioxidants (Alhdad et al. 2013) and the possible 
toxicity of iron (Alhdad et al. 2015). There may also be costs in changes to the morphology of the rooting system.

Under flooded conditions, obtaining oxygen is more difficult than under non-flooded conditions because of the low diffusivity of oxygen in water. This can result in problems for the supply of energy, potential shortages of carbohydrate, toxicities of mineral elements, the generation of reactive oxygen species and even water deficits (Colmer and Voesenek 2009). Consequently, many wetland species have root systems with high porosities (up to about 50\%) because of the development of aerenchyma (Colmer 2003). There are, however, other species that are still tolerant of flooding but where root porosities are low. In such species, one of which is S. maritima, an alternative for the maintenance of oxygen supply is the development of roots that grow horizontally and close to the interface between the atmosphere and the water surface (Armstrong et al. 1991; Voesenek and BaileySerres 2015; Phukan et al. 2016). These surface or adventitious roots are induced by submergence or ethylene (Sauter 2013; Voesenek and Bailey-Serres 2015; Phukan et al. 2016) and are more common amongst species with low root porosities to gases (little or no aerenchyma) than species with higher porosities (Armstrong et al. 1991). In these species, the primary root system is still required for anchorage and such roots are commonly thin (Armstrong et al. 1991, as is the case for S. maritima (Hajibagheri et al. 1985).

While adventitious roots may be a vital component of the root systems of some fresh-water wetland species, much less is known of these roots in salt-marsh halophytes (see Colmer and Flowers 2008), especially for dicotyledonous species. Although the growth of adventitious roots is negatively affected by the salinity of the flood water in some species (Colmer and Flowers 2008), Naidoo and Mundree (1993) reported that in Sporobolus virginicus grown under high salinity (400-mM $\mathrm{NaCl}$ ), waterlogging did not reduce the biomass of adventitious roots from that in the absence of salt. Recent studies of Song et al. (2011) have found that inland populations of Suaeda salsa adapt to the combination of waterlogging and salinity by producing adventitious roots. In both Cotula coronopifolia (Rich et al. 2012) and the flood-tolerant halophyte Tecticornia pergranulata (Rich et al. 2008; Pedersen et al. 2006), the adventitious roots contain chloroplasts in the cortical cells and are able to carry out photosynthesis, providing a source of oxygen to the waterlogged plants.

In the current paper, we have investigated whether adventitious roots play a role in tolerance to flooding in S. maritima, using plants grown in culture solutions. We hypothesised that plants growing under hypoxic conditions would produce adventitious roots or increase the proportion of adventitious roots relative to seminal roots. We also determined how flooding affects ion accumulation in the shoots (a determinant of growth of this species; Yeo and Flowers 1980) as part of an ongoing attempt to understand the limitations of low oxygen supply on a species that survives across a range of elevations in tidal marshes.

\section{Materials and Methods}

Plants of S maritima (L.) Dum. were grown from seed collected from Cuckmere Haven, East Sussex, UK (TQ515978; 51 39' $\left.31^{\prime \prime} \mathrm{N}, 000^{\circ} 11^{\prime} 20^{\prime \prime} \mathrm{E}\right)$. Seeds were germinated in sand and irrigated with culture solutions (see below) for 4 weeks before being transferred to plastic pots $(9 \mathrm{~cm}$ deep and $9 \mathrm{~cm}$ diameter at the top) containing silver sand. Each pot, containing one plant, was allocated to one of six different treatments (see below), with 20 pots per treatment. Plants were supplied with nutrients from the culture solution formulated by Stout and Arnon (1939). Further experiments were also carried out where nutrients were supplied by a modified Hoagland solution (see Wang et al. 2007) and a formulation of Yoshida et al. (1972) designed to mimic the nutrients available to rice in a paddy field. The Stout and Arnon solution, used in early experiments on S. maritima (e.g. Flowers 1972; Yeo and Flowers 1980), supplied $\mathrm{N}$ as nitrate alone, while the Hoagland and the Yoshida solutions contain both nitrate and ammonium ions; the Yoshida solution is more dilute than the Stout and Arnon and the Hoagland solutions (Supplementary Table S1).

Plants grown in the Stout and Arnon solution were in one of three dilutions $\left(100,200\right.$ or $400 \mathrm{mM} \mathrm{Na}{ }^{+}$) of seawater supplied under drained or flooded conditions (the 6 treatments) in a glasshouse $(16 / 8 \mathrm{~h} \mathrm{light/darkness,} \mathrm{temperature}$ range from $24.0-28.5^{\circ} \mathrm{C}$ with $60-75 \%$ relative humidity). The seawater was collected from the English Channel (at $36^{\circ} 16^{\prime} 15^{\prime \prime} \mathrm{N}, 59^{\circ} 38^{\prime} 30^{\prime \prime} \mathrm{W}$ ) and stored at the Brighton Aquarium (Brighton, East Sussex, UK) prior to use. The salinity required for the experiments (equivalent to 100 , 200 and $400 \mathrm{mM} \mathrm{Na}^{+}$) was achieved by diluting fresh filtered seawater with de-ionised water. Pots were transferred from 100 to 200 to $400 \mathrm{mM} \mathrm{Na}^{+}$in fresh seawater, until the treatment concentrations were reached ( 3 days for $400 \mathrm{mM}$ $\mathrm{Na}^{+}$). The flooding treatments were imposed by placing the pots at one of two heights in tanks in an irrigation system described by Wetson and Flowers (2010). Briefly, tanks containing the pots of plants were $1 \mathrm{~m}$ above reservoirs containing the culture solution in seawater (Fig. S1). This solution was pumped twice daily to the upper tanks, taking about $20 \mathrm{~min}$ to flood and $20 \mathrm{~min}$ to drain. Some pots (lower height) were permanently flooded and others flooded for about 40 min twice a day: more detail can be found in Alhdad et al. (2013). Plants from all experiments were harvested after 8 weeks of treatments, at which point the redox potential (Table 1) in the sand was recorded. The shoots and roots were washed, and the seminal and adventitious roots (see Fig. S2) were separated and the shoots weighed. Shoots and roots were then placed in an oven (Ohaus, Switzerland) 
Table 1 Mean Eh values $(\mathrm{mV})$ recorded at three depths (high, mid and low) in pots of sand in which $S$. maritima was growing at high-tide (drained), and low-tide (flooded) positions in the tidal flow glasshouse tank system in Stout and Arnon culture solution with different concentration of $\mathrm{Na}^{+}(100,200$ and $400 \mathrm{mM})$, in seawater

\begin{tabular}{|c|c|c|c|c|c|c|c|c|c|c|c|c|}
\hline \multirow{2}{*}{$\begin{array}{l}\text { Treatment } \\
\mathrm{Na}^{+}(\mathrm{mM})\end{array}$} & \multicolumn{6}{|l|}{ Drained } & \multicolumn{6}{|l|}{ Flooded } \\
\hline & Top & & Middle & & Bottom & & Top & & Middle & & bottom & \\
\hline & After & Before & After & Before & After & Before & After & Before & After & Before & After & Before \\
\hline 100 & $124 \pm 10$ & $136 \pm 8$ & $78 \pm 13$ & $96 \pm 10$ & $23 \pm 2$ & $61 \pm 15$ & $101 \pm 14$ & $87 \pm 14$ & $36 \pm 17$ & $10 \pm 20$ & $-133 \pm 2$ & $-142 \pm 2$ \\
\hline 200 & $79 \pm 11$ & $107 \pm 7$ & $11 \pm 12$ & $58 \pm 10$ & $-35 \pm 2$ & $8 \pm 13$ & $77 \pm 15$ & $73 \pm 13$ & $60 \pm 21$ & $15 \pm 20$ & $-176 \pm 3$ & $-155 \pm 2$ \\
\hline 400 & $66 \pm 10$ & $104 \pm 8$ & $15 \pm 15$ & $64 \pm 12$ & $-12 \pm 2$ & $21 \pm 15$ & $95 \pm 10$ & $85 \pm 12$ & $39 \pm 15$ & $35 \pm 16$ & $-37 \pm 2$ & $-36 \pm 2$ \\
\hline
\end{tabular}

The Eh of the sand in the pots surrounding the roots was measured at three depths, before and after flooding: in the top $1 \mathrm{~cm}$ of the sand, in the middle of the pots (about $4 \mathrm{~cm}$ below the surface) and at the bottom of the pots (about $8 \mathrm{~cm}$ below the surface)

at $80{ }^{\circ} \mathrm{C}$ for $72 \mathrm{~h}$, after which time they were weighed to determine the dry weight.

\subsection{Ion Contents}

Ion concentrations in the shoots were measured after grinding dried material with a mill (Glen Creston, Model DFH48, Stanmore, London, UK). Extracts were prepared by weighing powdered samples $(15 \mathrm{mg})$ into test tubes and heating with distilled water $(10 \mathrm{ml})$ in a water bath, maintained at a temperature of $90^{\circ} \mathrm{C}$. After $2 \mathrm{~h}$, the solution was filtered through Ashless No.1 $(90 \mathrm{~mm})$ filter paper and the filtrate analysed for $\mathrm{Na}^{+}, \mathrm{Ca}^{2+}, \mathrm{Mg}^{2+}$ and $\mathrm{K}^{+}: \mathrm{Na}^{+}$and $\mathrm{K}^{+}$by flame emission spectrophotometry (Eppendorf or Pye Unicam SP 90 A) and $\mathrm{Ca}^{2+}$ and $\mathrm{Mg}^{2+}$ by atomic absorption spectrophotometry (Pye Unicam SP 90 A).

\subsection{Gas Exchange}

Transpiration, net photosynthesis and stomatal conductance were measured over $2 \mathrm{~h}$, on three fully expanded healthy leaves of three plants of similar size, using a portable infrared gas analyser (CIRAS-2, PP systems, UK). Three plants were analysed per salt treatment over 3 days; one leaf was placed into the leaf cuvette [(PLC6 (U) Automatic Universal Leaf Cuvette), which had integrated temperature control and sensors for photosynthetically active radiation (PAR)] at $200 \mu \mathrm{mol} \mathrm{m} \mathrm{s}^{-1}$. The measurements were taken during the day at $22{ }^{\circ} \mathrm{C}$ and $60 \%$ relative humidity. Transpiration, photosynthesis and stomatal conductance were calculated per unit leaf area (single surface), which was estimated as described below (Siadat-Pour 1978).

\subsection{Leaf Area}

Leaf area was calculated as a half cylinder from leaves that were selected randomly from the plants. The length (L) and the mean value of the width (the diameter, D) of each leaf was measured using a travelling micrometre. The surface area (A) was calculated as: $A=\frac{D \pi L}{2}+D L$ (Siadat-Pour 1978).

\subsection{Stomatal Frequency}

The same plants used for measuring gas exchange were used for determining the number of stomata on adaxial and abaxial leaf surfaces from stomatal impressions taken using Elite fast hydrosystem impression material containing vinyl polysiloxane (VPIM, obtained from 3 M Dental Products, St. Paul, ISO Spec. 4823, type 3-Category A). After curing ( $2 \mathrm{~min}$ ), the VPIM was carefully removed from the leaf, coated with clear nail varnish and left for $5 \mathrm{~min}$ to dry. The film of nail varnish was carefully peeled from the VPIM, mounted on a microscope slide and the number of stomata counted (Reichert MicroStar IV light microscope) in 20 fields per sample at a magnification of $20 x$.

\subsection{Statistical Analysis}

All the experiments were repeated at least twice. The results are averages from within an experiment. Data were analysed by ANOVA using SPSS v 18. Different letters above the bars on graphs or after figures in tables indicate a significant difference in means from post hoc Tukey tests.

\section{Results}

\subsection{Plant Growth}

In our experiments conducted using Stout and Arnon (1939) solution, shoot dry weight was maximal in $200 \mathrm{mM} \mathrm{Na}^{+}$in seawater: growth in drained conditions in $100 \mathrm{mM}$ and $400 \mathrm{mM} \mathrm{Na}^{+}$was $53 \%$ and $71 \%$ of that at $200 \mathrm{mM} \mathrm{Na}^{+}$, respectively (Fig. 1). Subjecting plants to hypoxia reduced growth such that shoot dry weight at the optimal salinity decreased by about two thirds: shoot dry weight at $100 \mathrm{mM}$ and 


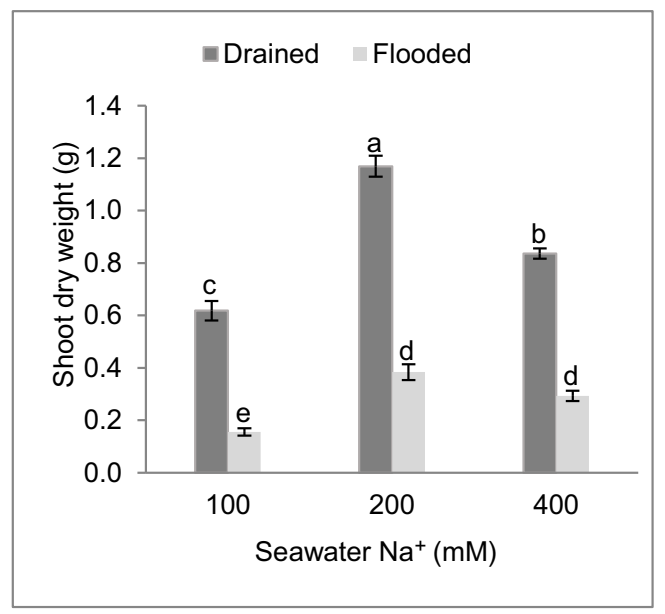

Fig. 1 Shoot dry weight (g per plant) of $S$. maritima plants grown under different concentrations of $\mathrm{Na}^{+}(100,200$ and $400 \mathrm{mM})$ in seawater in Stout and Arnon culture solution. Plants were grown under drained and flooded conditions, for 8 weeks in a glasshouse. Letters above error bars $(n=40)$ indicate significant difference in means from post hoc Tukey tests $(P<0.05)$

$400 \mathrm{mM}$ was $36 \%$ and $77 \%$ of that at $200 \mathrm{mM} \mathrm{Na}$, respectively.

Under well-drained conditions, the pattern of shoot growth (dry weight) in Hoagland solution was similar to that found in Stout and Arnon solution (Table S2). However, in Yoshida solution, growth was optimal in $450 \mathrm{mM} \mathrm{Na}^{+}$(Table S2). Flooding reduced growth in Hoagland and Yoshida solution producing a similar pattern of response to that in Stout and Arnon solution (compare Fig. 1 and Table S2).

\subsection{Root Biomass}

Plants of S. maritima produced a greater mass of adventitious than seminal roots in culture (compare Fig. 2a and b). The weight of adventitious roots was largely unaffected by salinity under drained conditions (Fig.2a), but was reduced under flooded conditions, where the maximal value was in $200 \mathrm{mM} \mathrm{Na}^{+}$(Fig. 2a). Seminal root mass was reduced by

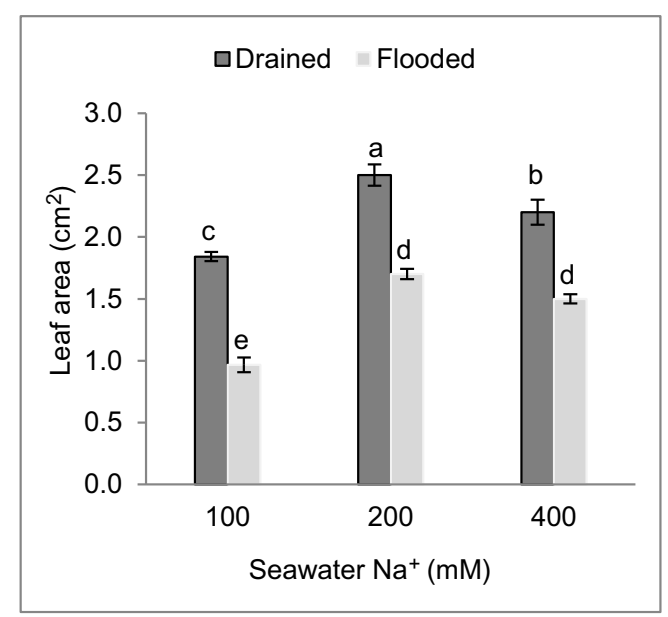

Fig. 3 Area per leaf $\left(\mathrm{cm}^{2}\right.$, mean of 30 leaves) of S. maritima grown under different concentrations of $\mathrm{Na}^{+}(100,200$ and $400 \mathrm{mM})$ in seawater in Stout and Arnon culture solution. Plants were grown under drained and flooded conditions for 8 weeks in a glasshouse. Letters above error bars $(n=30)$ indicate significant difference in means from post hoc Tukey tests $(P<0.05)$

salinity and flooding (Fig. 2b). On average, across all plants grown in Stout and Arnon solution, adventitious roots outweighed seminal roots by a factor of 15 . Plants grown in aerated conditions had 20 times greater dry weight of adventitious than seminal roots while in flooded conditions, across all salt concentrations, this ratio dropped to 10 . As in the Stout and Arnon solution, plants produced a greater mass of adventitious than seminal roots in both Hoagland and Yoshida solutions and flooding reduced the weight of adventitious roots in all three salinities tested (Table S2).

\subsection{Leaf Area}

Salt concentration significantly affected leaf area $(P<0.001$; Fig. 3), with the highest value recorded in $200 \mathrm{mM} \mathrm{Na}^{+}$, in both aerated and flooded conditions $(P<0.05)$. In flooded conditions, leaf area decreased compared to aerated conditions $(P<0.001)$ at all salt concentrations (Fig. 3$)$. In both the
Fig. 2 Dry weights of adventitious and seminal roots (both expressed as g per plant) of S. maritima grown under different concentrations of $\mathrm{Na}^{+}(100,200$ and $400 \mathrm{mM}$ ) in seawater in Stout and Arnon culture solution. Plants were grown under drained and flooded conditions for 8 weeks in a glasshouse. Letters above error bars $(n=20)$ indicate significant difference in means from post hoc Tukey tests $(P<0.05)$
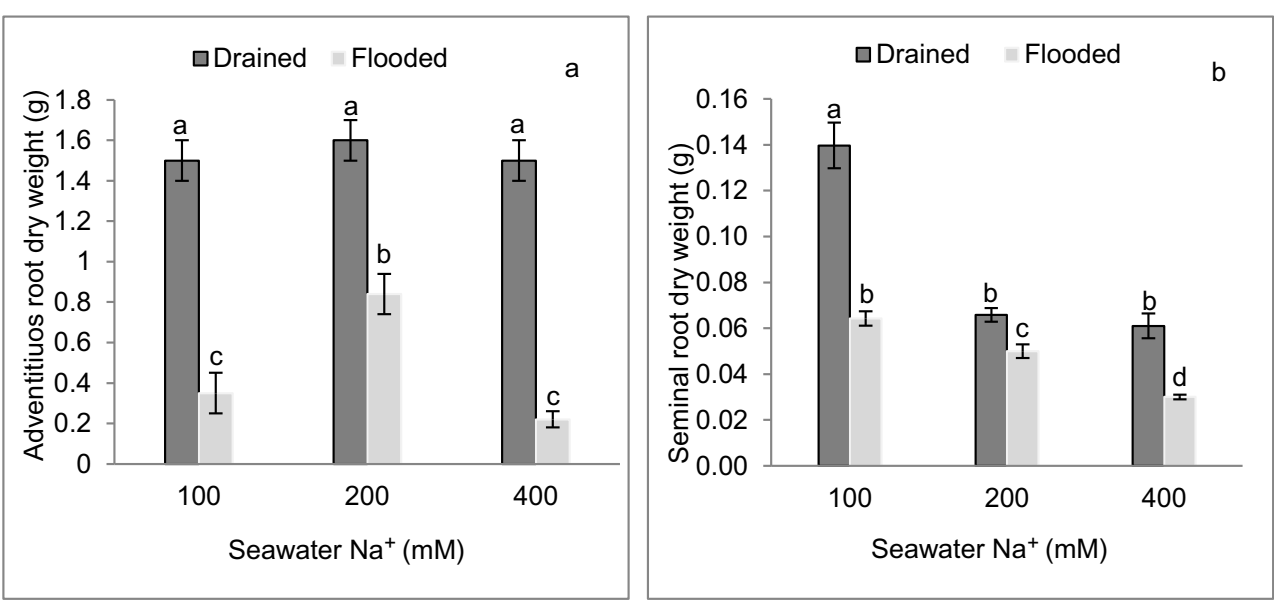
Fig. 4 Number of stomata on the abaxial and adaxial leaf surfaces of $S$. maritima (expressed per $\mathrm{mm}^{2}$ of leaf area) for plants grown under different concentrations of $\mathrm{Na}^{+}(100,200$ and $400 \mathrm{mM})$ in seawater in Stout and Arnon culture solution. Plants were grown, under drained and flooded conditions for 8 weeks in a glasshouse. Letters above error bars $(n=60)$ indicate significant difference in means from post hoc Tukey tests $(P<0.05)$
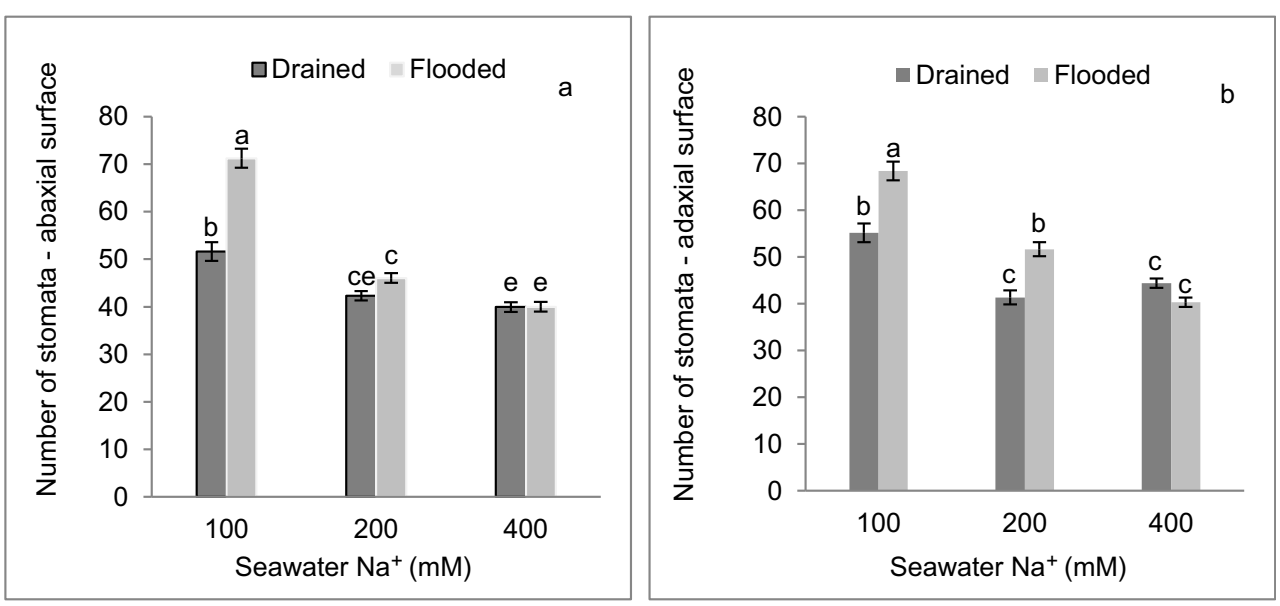

Hoagland and the Yoshida solutions, leaf area reflected growth (compare Tables S2 and S3).

\subsection{Number of Stomata}

Increasing salt concentration in the root medium decreased the frequency of stomata on both leaf surfaces in drained and flooded conditions in the Stout and Arnon solution $(P<0.05$; Fig. $4 \mathrm{a}$ and $\mathrm{b})$. Flooding increased the frequency of stomata, but as the salt concentration increased, the effect of flooding was reduced (Fig. 4a and b). Flooding tended to increase stomatal frequency in Hoagland's solution, but had less effect or reduced frequency at higher salinities in Yoshida solution (Table S3).

\subsection{Gas Exchange}

Stomatal conductance and transpiration rates for plants grown in Stout and Arnon solution were reduced with increasing salt in the root medium under both drained and flooded conditions $(P<0.05$; Table 2$)$. However, the rate of photosynthesis was greater in $200 \mathrm{mM}$ and $400 \mathrm{mM} \mathrm{Na}^{+}$than in $100 \mathrm{mM} \mathrm{Na}^{+}$ under both drained and flooded conditions. The rate of photosynthesis was always lower under flooded than drained conditions $(P<0.05)$. The instantaneous water use efficiency (WUE) (CIRAS2) was greater in drained than in flooded conditions $(P<0.05)$, except in $100 \mathrm{mM}$ salt where there was no significant difference between drained and flooded treatments. WUE increased significantly $(P<0.05)$ with increased salt concentration in drained and in flooded conditions (although the difference between values in 200 and $400 \mathrm{mM} \mathrm{Na}^{+}$was not statistically significant under flooded conditions). At the higher salinities, flooding reduced the WUE. A similar pattern of change in WUE was seen in estimations made from measurements of water loss by weighing and dry weight change (data not presented).

\subsection{Ion Concentrations}

Increasing the external salt concentration significantly increased plant $\mathrm{Na}^{+}$concentration $(P<0.001$; Fig. 5a): However, waterlogging did not affect shoot $\mathrm{Na}^{+}$significantly

Table 2 Gas exchange in S. maritima grown under different concentrations of $\mathrm{Na}^{+}(100,200$ and $400 \mathrm{mM})$, in seawater in Stout and Arnon culture solution

\begin{tabular}{|c|c|c|c|c|c|c|}
\hline \multirow[t]{2}{*}{ Parameterltreatment } & \multicolumn{2}{|l|}{$\mathrm{Na}^{+} 100 \mathrm{mM}$} & \multicolumn{2}{|l|}{$\mathrm{Na}^{+} 200 \mathrm{mM}$} & \multicolumn{2}{|l|}{$\mathrm{Na}^{+} 400 \mathrm{mM}$} \\
\hline & Drained & Flooded & Drained & Flooded & Drained & Flooded \\
\hline $\begin{array}{l}\text { Stomatal conductance } \\
\left(\mathrm{mol} \mathrm{m}^{-2} \mathrm{~s}^{-1}\right)\end{array}$ & $53 \pm 4 \mathrm{a}$ & $29.4 \pm 2 c$ & $36.1 \pm 1 b$ & $25.3 \pm 1 d$ & $28.4 \pm 2 \mathrm{c}$ & $23.8 \pm 0.6 \mathrm{~d}$ \\
\hline $\begin{array}{l}\text { Transpiration } \\
\left(\mathrm{mmol} \mathrm{m} \mathrm{m}^{-2} \mathrm{~s}^{-1}\right)\end{array}$ & $0.70 \pm 0.02 \mathrm{a}$ & $0.42 \pm 0.02 \mathrm{c}$ & $0.51 \pm 0.01 b$ & $0.41 \pm 0.03 \mathrm{c}$ & $0.39 \pm 0.01 \mathrm{c}$ & $0.32 \pm 0.01 \mathrm{~d}$ \\
\hline $\begin{array}{l}\text { Photosynthesis } \\
\left(\mu \mathrm{mol} \mathrm{m} \mathrm{s}^{-1}\right)\end{array}$ & $0.50 \pm 0.05 \mathrm{~b}$ & $0.27 \pm 0.02 \mathrm{c}$ & $0.74 \pm 0.07 \mathrm{a}$ & $0.47 \pm 0.04 \mathrm{~b}$ & $0.72 \pm 0.02 \mathrm{a}$ & $0.40 \pm 0.02 \mathrm{~b}$ \\
\hline Instantaneous water use efficiency & $0.68 \pm 0.08 \mathrm{~d}$ & $0.65 \pm 0.04 \mathrm{~d}$ & $1.56 \pm 0.02 b$ & $1.15 \pm 0.1 \mathrm{c}$ & $1.8 \pm 0.06 \mathrm{a}$ & $1.28 \pm 0.08 \mathrm{c}$ \\
\hline
\end{tabular}

Letters indicate significant difference in means from post hoc Tukey tests $(P<0.05)$

Plants were grown under drained and flooded conditions for 8 weeks in a glasshouse. Values are means \pm standard error $(n=16)$. Water use efficiency was determined from the instantaneous gas exchange measurements $\left(\mathrm{mmol} \mathrm{CO}_{2} \mathrm{~m}^{-2} \mathrm{~s}^{-1} / \mathrm{mmol} \mathrm{H}_{2} \mathrm{O} \mathrm{m}^{-2} \mathrm{~s}^{-1}\right)$ 
Fig. 5 Shoot $\mathrm{Na}^{+}$and $\mathrm{K}^{+}$ concentrations (expressed on the basis of dry weight) of S. maritima grown under different concentrations of $\mathrm{Na}^{+}(100,200$ and $400 \mathrm{mM}$ ) in seawater in Stout and Arnon culture solution. Plants were grown under drained and flooded conditions for 8 weeks in a glasshouse. Letters above error bars $(n=40)$ indicate significant difference in means from post hoc Tukey tests $(P<0.05)$
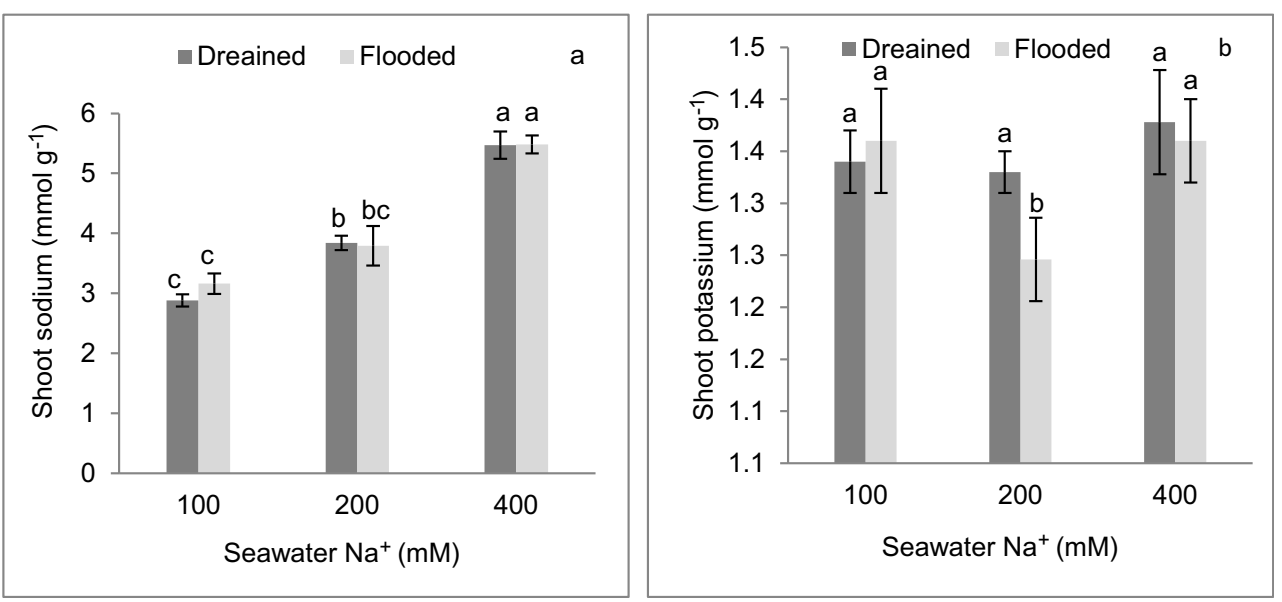

$(P=0.286)$. Shoot $\mathrm{K}^{+}$concentrations were a little lower under flooded than well-drained conditions at external $\mathrm{Na}^{+}$concentrations above $100 \mathrm{mM} \mathrm{Na}^{+}$(Fig. 5b). In Hoagland and Yoshida solutions, shoot $\mathrm{Na}^{+}$concentrations were similar to those in Stout and Arnon solution, but $\mathrm{Na}^{+}$was a little lower under flooded than well-drained conditions (Table S4). Shoot $\mathrm{K}^{+}$concentrations tended to be reduced by increased external salinity and by flooding in both culture solutions (Table S4). No significant trends were seen for the concentrations of $\mathrm{Ca}^{2+}$ or $\mathrm{Mg}^{2+}$ (Table S4).

\section{Discussion}

Growth of S. maritima was affected both by flooding and by salinity. In our experiments, growth of S. maritima was maximal in $200 \mathrm{mM} \mathrm{Na}^{+}$in both Stout and Arnon and Hoagland solutions in both well-drained and flooded conditions. Previously published optimal salinities for the growth of $S$ maritima range from 170 (Flowers 1972; Yeo and Flowers 1980; 3-week-old plants treated for 5 weeks) to $400 \mathrm{mM}$ $\mathrm{NaC}$ (Winter 1974; plants treated for 4 weeks in a solution containing ammonium ions - see Winter 1973). The reasons for these differences are likely to reflect the environmental conditions, the age of the plants at harvest and the nature of the medium in which the plants were grown. For example, plants grew less well (were smaller) in Yoshida than Hoagland and Stout and Arnon solutions, with lower S/R ratios. Furthermore, growth in well-drained Yoshida solution was maximal at $450 \mathrm{Na}^{+} \mathrm{mM}$ rather than $200 \mathrm{mM} \mathrm{Na}^{+}$. The Yoshida solution has lower nutrient concentrations than the Stout and Arnon and the Hoagland formulations and the plants increased root relative to shoot growth in the Yoshida solution compared to the other two formulations.

The differences in growth in different salinities raises a question about what constitutes a 'control' solution for the growth of a euhalophyte such as S. maritima. In our experiments, we used three salt concentrations under which we evaluated the response to hypoxia; concentrations below (i.e. $100 \mathrm{mM} \mathrm{Na}^{+}$) and above (i.e. $400 \mathrm{mM} \mathrm{Na}^{+}$) the optimal concentration for the growth of $S$. maritima $\left(200 \mathrm{mM} \mathrm{Na}^{+}\right.$, in our experiments). We deliberately did not attempt to grow plants in the absence of salt (what would be a control solution for a glycophyte), as this is a nutrient-deficient solution for this species. As Yeo and Flowers (1980) pointed out, solutions of below about $100 \mathrm{mM}$ are, formally, nutrient deficient in that they depress the maximum growth potential of S. maritima. A further reason for avoiding a $\mathrm{Na}^{+}-$free solution is that such conditions are unlikely to occur naturally on saltmarshes, the habitat for S. maritima, where the minimal salt concentration is around $100 \mathrm{mM} \mathrm{Na}^{+}$(Table 4 in Flowers 1985).

Under natural conditions, plants of S. maritima that grew on the lower elevations of a salt marsh, where they were frequently submerged, were smaller than those growing higher up the marsh (Wetson and Flowers 2010; Alhdad et al. 2013). This response has been be replicated under artificial conditions, where growth was reduced by flooding compared with well drained conditions (Wetson and Flowers 2010; Wetson et al. 2012; Alhdad et al. 2015); this is confirmed in our experiments (Fig. 1 and Table S2). The response to flooding appears ubiquitous as it ocurred both in the presence and absence of $\mathrm{NH}_{4}{ }^{+}$in the culture solution (Stout and Arnon and Hoagland, respectively) and where the concentration of nutrient ions was low (Yoshida solution). A reduction in leaf area under flooded as opposed to well-drained conditions (Fig. 3), together with reduced rates of photosynthesis and WUE (Table 2) would have contributed to the reduced growth under flooded conditions. Stomatal frequency fell with increasing salinity, but was slightly higher under flooded rther than welldrained conditions; this was likely a consequence of the decreased leaf area brought about by flooding after the time at which stomatal numbers per leaf were fixed. Transpiration was also reduced by flooding, which would have reduced the flux of ions from roots to shoots; growth of S. maritima is closely coupled to the flux of $\mathrm{Na}^{+}$from roots to shoots (Yeo and Flowers 1980, 1986). 
Table 3 Sodium ion fluxes in shoots of $S$. maritima grown under different concentrations of $\mathrm{Na}^{+}(100,200$ and $400 \mathrm{mM})$ in seawater in Stout and Arnon culture solution

\begin{tabular}{|c|c|c|c|c|c|c|c|}
\hline & \multirow[t]{2}{*}{ Treatment } & \multicolumn{2}{|c|}{$\mathrm{Na}^{+} 100 \mathrm{mM}$} & \multicolumn{2}{|c|}{$\mathrm{Na}^{+} 200 \mathrm{mM}$} & \multicolumn{2}{|c|}{$\mathrm{Na}^{+} 400 \mathrm{mM}$} \\
\hline & & Drained & Flooded & Drained & Flooded & Drained & Flooded \\
\hline Na flux $\left(\mathrm{mmol} \mathrm{g}^{-1} \mathrm{~d}^{-1}\right)$ & & 3.9 & 2.6 & 4.1 & 3.6 & 8.2 & 7.5 \\
\hline
\end{tabular}

Ion fluxes $(\mathrm{J})=\mathrm{M} 2-\mathrm{M} 1 / \mathrm{W}(\mathrm{T} 2-\mathrm{T} 1)$ where $\mathrm{W}=[(\mathrm{W} 2-\mathrm{W} 1) / \operatorname{loge}(\mathrm{W} 2 / \mathrm{W} 1)]$. M1 and M2 are the ion contents at times T2 and T1 while W is the average weight of roots or shoots between harvests (Ansari 1982)

Plants were grown under drained and flooded conditions for 8 weeks in a glasshouse and fluxes are in units of mmol of $\mathrm{Na}^{+}$reaching the shoots expressed per $\mathrm{g}$ dry weight of roots per day
In well-drained conditions, $\mathrm{Na}^{+}$fluxes for plants in Stout and Arnon solution reached values of around $8 \mathrm{mmol} \mathrm{g}^{-1}$ dry weight $\mathrm{d}^{-1}$ in $400 \mathrm{mM} \mathrm{Na}^{+}$(Table 3 ), similar to values of about $9 \mathrm{mmol} \mathrm{g}^{-1}$ dry weight $\mathrm{d}^{-1}$ recorded by Yeo and Flowers (1986). In our experiments, fluxes of $\mathrm{Na}^{+}$in flooded conditions were lower than under well-drained conditions, but because of reduced growth this did not lead to significantly lower $\mathrm{Na}^{+}$concentrations in the shoots of plants grown in Stout and Arnon solution (Fig. 5a). However, in the two ammonium-containing solutions (Yoshida and Hoagland) there was, in general, a decrease in shoot $\mathrm{Na}^{+}$under waterlogging, (Table S4). If the $\mathrm{NH}_{4}{ }^{+}$ions were to be taken up preferentially to $\mathrm{NO}_{3}{ }^{+}$, this would tend to acidify the rhizosphere, altering the driving force for the entry of $\mathrm{Na}^{+}$and perhaps explain the differences between the responses. Where hypoxia is severe, plants of $S$. maritima do show increased $\mathrm{Na}^{+}$and reduced $\mathrm{K}^{+}$concentrations under flooded conditions (Wetson and Flowers 2010; Behr et al. 2017). In our culture conditions, the minimal $\mathrm{Eh}$ value recorded $(-176 \mathrm{mV}$, Table 1) was low enough (below $-100 \mathrm{mV}$ ) to elicit this response (cf. Wetson and Flowers 2010). However, such low values only ocurred at the bottom of the pots; the Eh values were significantly higher in the sand at the top and middle of the pots (Table 1). Wetson and Flowers (2010) argued from measurement of short-term influx with ${ }^{22} \mathrm{Na}^{+}$that "influx under hypoxia occurs by a different pathway from that under normoxic conditions".

Under flooded conditions, oxygen and ATP are less available than under well drained conditions, generating what Greenway and Armstrong (2018) have called an energy crisis. The production of adventitious roots at the soil/atmosphere boundary is a predictable adaptation to increase oxygen supply (Sauter 2013) and avoid a diurnal energy crisis, but this is not the response seen for $S$. maritima, where the mass of adventitious roots reduced rather than increased under flooding. However, the roots of $S$. maritima show a remarkable adaptation to hypoxia, fermentative metabolism to lactate: the concentration of lactate present in the roots of S. maritima is an order of magnitude higher than found in other plant species. This suggests these plants have evolved a biochemical rather than a morphological solution to the generation of ATP under conditions of transiently low oxygen concentrations (Colmer et al.
2013) - albeit producing reduced amounts of ATP with reduced growth compared with normoxic conditions.

The growth of other species of Suaeda is also affected by flooding. Growth of the perennial shrub $S$. aegyptiaca was reduced by waterlogging, although the data were only obtained in the absence of salinity (Ibrahim 2013). Growth of Suaeda glauca, an annual species found widely in coastal regions of China, was also reduced by waterlogging (Duan et al. 2018); for this species, there was no effect of flooding treatment on $\mathrm{Na}^{+}$concentrations in the shoots, although $\mathrm{Cl}$ concentrations were elevated and could have been a cause of ion toxicity. In $S$. salsa, growing in a coastal wetland in China, Guan et al. (2011) reported the leaf $\mathrm{Na}^{+}$concentrations to be increased by waterlogging, while $\mathrm{Ca}^{2+}$ and $\mathrm{Mg}^{2+}$ concentrations were reduced. $S$. salsa is an annual species with both inter-tidal and inland populations in China (Song 2009). The inland population was more sensitive to waterlogging than the coastal population, but waterlogging only reduced the the shoot $\mathrm{Na}^{+}$concentration at the highest salinity tested $(600 \mathrm{mM} \mathrm{NaCl})$ in the intertidal polutation and had no effect on the $\mathrm{Cl}^{-}$concentrations (Song 2009). Interestingly, for S. salsa, coastal populations did not produce adventitious roots, but waterlogging induced the emergence of adventitious roots in the inland population (Song et al. 2011), mediated by NO signalling (Chen et al. 2016). For S. maritima, flooding, in general, reduced the weight of adventitious roots with little effect on seminal roots. It appears that the growth of adventitious roots of closely related species of Suaeda (S. maritima and $S$. salsa) is surprisingly different. The reasons for the reduction in the proportion of adventitious roots in $S$. maritima are unclear, but the same response occurred in culture solutions of different ionic strength and species of $\mathrm{N}$ available.

\section{Conclusions}

It is clear that the growth of $S$. maritima is reduced by flooding (generally to about one-third of the growth under well-aerated conditions) regardless of the culture conditions. The unusual feature of $S$. maritima growing under flooded conditions is a reduction in the 
production of adventitious roots and a reliance on the seminal root system, resulting in us rejecting our hypothesis of increased production of adventitious roots. This may reflect the unusually high levels of lactate metabolism in this species. However, there is an unfortunate dearth of information in the literature related to the interaction of flooding and salinity on root development in halophytes.

Supplementary Information The online version contains supplementary material available at https://doi.org/10.1007/s42729-020-00384-x.

\section{Compliance with Ethical Standards}

Conflict of Interest On behalf of both authors, the corresponding author states that there is no conflict of interest.

Open Access This article is licensed under a Creative Commons Attribution 4.0 International License, which permits use, sharing, adaptation, distribution and reproduction in any medium or format, as long as you give appropriate credit to the original author(s) and the source, provide a link to the Creative Commons licence, and indicate if changes were made. The images or other third party material in this article are included in the article's Creative Commons licence, unless indicated otherwise in a credit line to the material. If material is not included in the article's Creative Commons licence and your intended use is not permitted by statutory regulation or exceeds the permitted use, you will need to obtain permission directly from the copyright holder. To view a copy of this licence, visit http://creativecommons.org/licenses/by/4.0/.

\section{References}

Alhdad GM, Seal CE, Al-Azzawi MJ, Flowers TJ (2013) The effect of combined salinity and waterlogging on the halophyte Suaeda maritima: the role of antioxidants. Environ Exp Bot 87:120-125. https://doi.org/10.1016/j.envexpbot.2012.10.010

Alhdad GM, Zoerb C, Al-Azzawi MJ, Flowers TJ (2015) Is the reduced growth of the halophyte Suaeda maritima under hypoxia due to toxicity of iron or manganese? Environ Exp Bot 116:61-70. https://doi.org/10.1016/j.envexpbot.2015.03.002

Ansari R (1982) Salt tolerance studies in some halophytes. University of Sussex, Brighton, UK, DPhil

Armstrong W, Justin S, Beckett PM, Lythe S (1991) Root adaptation to soil waterlogging. Aquat Bot 39(1-2):57-73. https://doi.org/10. 1016/0304-3770(91)90022-w

Behr JH, Bouchereau A, Berardocco S, Seal CE, Flowers TJ, Zoerb C (2017) Metabolic and physiological adjustment of to combined salinity and hypoxia. Ann Bot 119(6):965-976. https://doi.org/10. 1093/aob/mcw282

Chen TS, Yuan F, Song J, Wang BS (2016) Nitric oxide participates in waterlogging tolerance through enhanced adventitious root formation in the euhalophyte Suaeda salsa. Funct Plant Biol 43(3):244 253. https://doi.org/10.1071/fp15120

Colmer TD (2003) Long-distance transport of gases in plants: a perspective on internal aeration and radial oxygen loss from roots. Plant Cell Environ 26(1):17-36

Colmer TD, Flowers TJ (2008) Flooding tolerance in halophytes. New Phytol 179(4):964-974. https://doi.org/10.1111/j.1469-8137.2008. 02483.x
Colmer TD, Voesenek L (2009) Flooding tolerance: suites of plant traits in variable environments. Funct Plant Biol 36(8):665-681. https:// doi.org/10.1071/fp09144

Colmer TD, Pedersen O, Wetson AM, Flowers TJ (2013) Oxygen dynamics in a salt-marsh soil and in Suaeda maritima during tidal submergence. Environ Exp Bot 92:73-82. https://doi.org/10.1016/ j.envexpbot.2012.07.002

Duan HM, Ma YC, Liu RR, Li Q, Yang Y, Song J (2018) Effect of combined waterlogging and salinity stresses on euhalophyte Suaeda glauca. Plant Physiol. Biochem.127:231-237. https://doi. org/10.1016/j.plaphy.2018.03.030

Flowers TJ (1972) Salt tolerance in Suaeda maritima (L) Dum. The effect of sodium chloride on growth respiration and soluble enzymes in a comparative study with Pisum sativum L. J Exp Bot 23:310-321

Flowers TJ (1985) Physiology of halophytes Plant and Soil 89:41-56

Greenway H, Armstrong W (2018) Energy-crises in well-aerated and anoxic tissue: does tolerance require the same specific proteins and energy-efficient transport? Funct. Plant Biol 45(9):877-894. https:// doi.org/10.1071/fp17250

Guan B, Yu JB, Wang XH, Fu YQ, Kan XY, Lin QX, Han GX, Lu ZH (2011) Physiological responses of halophyte Suaeda salsa to water table and salt stresses in coastal wetland of yellow river delta. Clean (Weinh) 39(12):1029-1035. https://doi.org/10.1002/clen. 201000557

Hajibagheri MA, Yeo AR, Flowers TJ (1985) Salt tolerance in the halophyte Suaeda maritima (L) Dum. Fine structure and ion concentrations in the apical region of the roots. New Phytol 99:331-343

Ibrahim AH (2013) Tolerance and avoidance responses to salinity and water stresses in Calotropis procera and Suaeda aegyptiaca. Turk J Agric For 37(3):352-360. https://doi.org/10.3906/tar-1202-62

Naidoo G, Mundree SG (1993) Relationship between morphological and physiological responses to waterlogging and salinity in Sporobolus virginicus (L.) Kunth. Oecologia 93(3):360-366. https://doi.org/10. 1007/bf00317879

Pedersen O, Vos H, Colmer TD (2006) Oxygen dynamics during submergence in the halophytic stem succulent Halosarcia pergranulata. Plant Cell Environ 29(7):1388-1399. https://doi.org/ 10.1111/j.1365-3040.2006.01522.x

Phukan UJ, Mishra S, Shukla RK (2016) Waterlogging and submergence stress: affects and acclimation. Crit Rev Biotechnol 36(5):956-966. https://doi.org/10.3109/07388551.2015.1064856

Rich SM, Ludwig M, Colmer TD (2008) Photosynthesis in aquatic adventitious roots of the halophytic stem-succulent Tecticornia pergranulata (formerly Halosarcia pergranulata). Plant Cell Environ 31(7):1007-1016. https://doi.org/10.1111/j.1365-3040. 2008.01813.x

Rich SM, Ludwig M, Colmer TD (2012) Aquatic adventitious root development in partially and completely submerged wetland plants Cotula coronopifolia and Meionectes brownii. Ann. Bot. :1-10

Sauter M (2013) Root responses to flooding. Curr Opin Plant Biol 16(3): 282-286. https://doi.org/10.1016/j.pbi.2013.03.013

Siadat-Pour AA (1978) Physiological studies of Suaeda maritima (L.) Dum. D,Phil., University of Sussex

Song J (2009) Root morphology is related to the phenotypic variation in waterlogging tolerance of two populations of Suaeda salsa under salinity. Plant Soil 324(1-2):231-240. https://doi.org/10.1007/ s11104-009-9949-5

Song J, Shi GW, Gao B, Fan H, Wang BS (2011) Waterlogging and salinity effects on two Suaeda salsa populations. Physiol Plant 141(4):343-351. https://doi.org/10.1111/j.1399-3054.2011.01445.x

Stout PR, Arnon DI (1939) Experimental methods for the study of the role of copper, manganese, and zinc in the nutrition of higher plants. Am J Bot 26(3): 144-149. https://doi.org/10.2307/2436530

Tabot PT, Adams JB (2019) South African salt marshes: ecophysiology and ecology in the context of climate change. In: Hasanuzzaman M, Shabala S, Fujita M (eds) Halophytes and climate change: adaptive 
mechanisms and potential uses. CABI Publishing, Wallingford, pp 69-88

Voesenek L, Bailey-Serres J (2015) Flood adaptive traits and processes: an overview. New Phytol 206(1):57-73. https://doi.org/10.1111/ nph.13209

Wang SM, Zhang JL, Flowers TJ (2007) Low-affinity $\mathrm{Na}^{+}$uptake in the halophyte Suaeda maritima. Plant Physiol 145(2):559-571

Wetson AM, Flowers TJ (2010) The effect of saline hypoxia on growth and ion uptake in Suaeda maritima. Funct Plant Biol 37(7):646655. https://doi.org/10.1071/fp09270

Wetson AM, Zorb C, John EA, Flowers TJ (2012) High phenotypic plasticity of Suaeda maritima observed under hypoxic conditions in relation to its physiological basis. Ann Bot 109(5):1027-1036. https://doi.org/10.1093/aob/mcs014

Winter K (1973) $\mathrm{CO}_{2}$-fixation metabolism in the halophytic species Mesembryanthemum crystallimun grown under different environmental conditions. Planta 114:75-85
Winter K (1974) Effect of NaCl-salinity on growth and photosynthesis in halophytes Mesembryanthemum nodiflorum L and Suaeda maritima (L) Dum. Oecologia 17(4):317-324. https://doi.org/10.1007/ bf00345749

Yeo AR, Flowers TJ (1980) Salt tolerance in the halophyte Suaeda maritima (L.) Dum.: evaluation of the effect of salinity upon growth. J Exp Bot 31:1171-1183

Yeo AR, Flowers TJ (1986) Ion transport in Suaeda maritima: its relation to growth and implications for the pathway of radial transport of ions across the root. J Exp Bot 37:143-159

Yoshida S, Forno DA, Cock JH, Gomez KA (1972) Laboratory manual for physiological studies of rice. IRRI 2nd Edition:1-70

Publisher's note Springer Nature remains neutral with regard to jurisdictional claims in published maps and institutional affiliations. 